\title{
Effects of cannabis on pulmonary structure, function and symptoms
}

\author{
Sarah Aldington, Mathew Williams, Mike Nowitz, Mark Weatherall, Alison Pritchard, Amanda \\ McNaughton, Geoffrey Robinson, Richard Beasley
}

Thorax 2007;62:1058-1063. doi: 10.1136/thx.2006.07708

See end of article for authors' affiliations

Correspondence to:

Professor Richard Beasley,

Medical Research Institute of

New Zealand, P O Box

10055, Wellington 6143,

New Zealand; Richard.

Beasley@mrinz.ac.nz

Received 28 December 2006 Accepted 6 June 2007

\begin{abstract}
Background: Cannabis is the most widely used illegal drug worldwide. Long-term use of cannabis is known to cause chronic bronchitis and airflow obstruction, but the prevalence of macroscopic emphysema, the doseresponse relationship and the dose equivalence of cannabis with tobacco has not been determined.

Methods: A convenience sample of adults from the Greater Wellington region was recruited into four smoking groups: cannabis only, tobacco only, combined cannabis and tobacco and non-smokers of either substance. Their respiratory status was assessed using high-resolution CT (HRCT) scanning, pulmonary function tests and a respiratory and smoking questionnaire. Associations between respiratory status and cannabis use were examined by analysis of covariance and logistic regression.

Results: 339 subjects were recruited into the four groups. A dose-response relationship was found between cannabis smoking and reduced forced expiratory volume in $1 \mathrm{~s}$ to forced vital capacity ratio and specific airways conductance, and increased total lung capacity. For measures of airflow obstruction, one cannabis joint had a similar effect to 2.5-5 tobacco cigarettes. Cannabis smoking was associated with decreased lung density on HRCT scans. Macroscopic emphysema was detected in 1/75 (1.3\%), 15/92 (16.3\%), 17/91 $(18.9 \%)$ and $0 / 81$ subjects in the cannabis only, combined cannabis and tobacco, tobacco alone and nonsmoking groups, respectively.

Conclusions: Smoking cannabis was associated with a dose-related impairment of large airways function resulting in airflow obstruction and hyperinflation. In contrast, cannabis smoking was seldom associated with macroscopic emphysema. The 1:2.5-5 dose equivalence between cannabis joints and tobacco cigarettes for adverse effects on lung function is of major public health significance.
\end{abstract}

C annabis is used by an estimated 160 million people worldwide. ${ }^{1}$ Concerns regarding its pulmonary effects arose from the observation that it is qualitatively similar to tobacco, with the exception of their respective tetrahydrocannabinol (THC) and nicotine components. ${ }^{2}$ This observation led to a series of cross-sectional and longitudinal studies which showed that long-term cannabis smoking results in chronic bronchitis $^{3-5}$ and airflow obstruction with impaired large airways function. ${ }^{6}$ However, other studies have failed to find an effect of cannabis smoking on lung function. ${ }^{7}$ These studies were limited by the unavailability of CT scanning to determine the presence of emphysema which a recent case series suggests may be associated with cannabis use. ${ }^{8}$ Importantly, it has not yet been possible to determine the dose-response relationship of long-term cannabis smoking with adverse respiratory effects using objective measures of pulmonary structure and function, or the dose equivalence of cannabis with tobacco consumption.

In this study, lung function tests, high resolution CT scans and detailed questionnaires were used to determine the association between cannabis smoking (with and without tobacco) on pulmonary structure, function and symptoms. This study was undertaken in New Zealand because of the high prevalence of cannabis smoking and the infrequent practice of combining cannabis and tobacco. ${ }^{9}$

\section{METHODS}

\section{Study population}

Phase I: Random sample

Participants in the Wellington Respiratory Survey were randomly selected from the electoral register, equally distributed by sex across the five 10-year age groups from 25 to
75 years. $^{10}{ }^{11}$ Subjects were sent a single page postal questionnaire seeking demographic, respiratory and smoking history data. Those who completed and returned their questionnaires were invited to undertake a detailed intervieweradministered questionnaire and investigative modules. Owing to the inadequate number of subjects who smoked cannabis in this random population sample, it was necessary to recruit a convenience sample for the study (see fig E2 in the online supplement available at http://thorax.bmj.com/supplemental). The results therefore pertain only to the convenience sample.

Phase II: convenience sample

A convenience sample of adults aged 18-70 years was recruited from the Greater Wellington area using newspaper and radio advertisements and through informal contacts. The stated purpose of the study was to investigate the health of cannabis smokers.

\section{Smoking categories}

Participants were recruited into four smoking categories: (1) cannabis only; (2) tobacco only; (3) combined cannabis and tobacco; and (4) non-smokers of either substance. Inclusion criteria for cannabis smokers and tobacco smokers were a lifetime exposure of at least 5 joint-years of cannabis or at least l pack-year of tobacco, respectively. A joint-year of cannabis

Abbreviations: COPD, chronic obstructive pulmonary disease; $\mathrm{FEV}_{1}$ forced expiratory volume in $1 \mathrm{~s}$; FRC, functional residual capacity; FVC, forced vital capacity; MMEF, maximum mid-expiratory flow; RV, residual volume; sGaw, specific airways conductance; SVC, slow vital capacity; THC, tetrahydrocannabinol; TLC, total lung capacity; TLCO, carbon monoxide transfer factor 
was defined as smoking one joint per day for 1 year and a packyear of tobacco was equivalent to smoking 20 tobacco cigarettes per day for 1 year. Non-smokers had a lifetime exposure of $<1$ pack-year of tobacco and $<20$ joints of cannabis.

Subjects were excluded if they had chronic lung disease (such as asthma, chronic bronchitis or cystic fibrosis) diagnosed by a doctor before the age of 16, were pregnant, were heterozygous or homozygous for $\alpha_{1}$-antitrypsin deficiency or they had used a substance of abuse other than cannabis, tobacco and alcohol $>12$ times in their lifetime. Subjects who claimed to be non-smokers were excluded as controls if they tested positive for urinary THC or cotinine.

\section{Lung function tests}

Participants underwent extensive pulmonary function testing using two Jaeger Master Screen Body volume constant plethysmography units (Masterlab 4.5 and 4.6 Erich-Jaeger, Wurtzberg, Germany). Tests performed included forced expiratory volume in $1 \mathrm{~s}\left(\mathrm{FEV}_{1}\right)$, forced vital capacity (FVC), maximum mid-expiratory flow (MMEF), slow vital capacity (SVC), total lung capacity (TLC), residual volume (RV), functional residual capacity (FRC), specific airways conductance (sGaw) and carbon monoxide transfer factor (TLCO). Lung function tests were carried out before and after the administration of $400 \mu \mathrm{g}$ salbutamol inhaled via a spacer device. TLCO measurements were corrected for haemoglobin and carboxyhaemoglobin and for lung volume to give the carbon monoxide transfer coefficient (TLCO/VA). Reference equations were those derived by the European Community for Coal and Steel. ${ }^{12}$

The lung function tests were conducted in accordance with American Thoracic Society ${ }^{13}$ and European Respiratory Society $^{15}$ guidelines and equipment was calibrated daily. Subjects were asked to refrain from caffeine and carbonated drinks for $6 \mathrm{~h}$ before testing and smokers were asked to refrain from tobacco for $2 \mathrm{~h}$ and cannabis for $6 \mathrm{~h}$ before testing. Shortacting bronchodilators were withheld for $6 \mathrm{~h}$ and long-acting bronchodilators for $36 \mathrm{~h}$ prior to testing. Testing was not carried out within 3 weeks of a respiratory tract infection.

\section{CT scanning}

Subjects were scanned, without contrast, using a single scanner (GE Prospeed, General Electrical Medical Systems, YMS, Japan) by two radiographers specifically trained in the study protocol. Scans were obtained at full inspiration with a breath hold time of $4.5 \mathrm{~s}$ ( $1 \mathrm{~mm}$ thickness high resolution axial images performed at $1 \mathrm{~cm}$ intervals with a $512 \times 512$ matrix, $\mathrm{kVp} 120$, Ma $>120$ ).

The three images obtained at levels $1 \mathrm{~cm}$ above the superior margin of the aortic arch, $1 \mathrm{~cm}$ below the carina and $3 \mathrm{~cm}$ above the top of the diaphragm were used for measurements of lung density using a density mask programme. The trachea and main stem bronchi were excluded from the measurements of lung area, and lung tissue was separated from the chest wall using a density of -300 to -1200 Hounsfield Units (HU) to calculate the total area of lung tissue per slice. The area below $-950 \mathrm{HU}$ was expressed as a percentage of total lung area for that slice (RA950) and as the mean of three slices. The apical slice of the HRCT scan was analysed as a separate variable as it has been shown to be a better discriminator between controls and subjects with chronic obstructive pulmonary disease (COPD).$^{10}$

All lung slices were subjectively analysed by two radiologists, blinded to the patient's smoking history, for the presence and severity of emphysema, the type and distribution of any emphysematous change and any other morphological changes in the lung.

\section{Other tests}

Blood samples were taken from all participants for measurement of haemoglobin, carboxyhaemoglobin and $\alpha_{1}$-antitrypsin levels. A urine sample was collected for measurement of THC and the tobacco metabolite cotinine for the purpose of validating the subject groups. Atopy was defined by a positive skin prick test to at least one common allergen or a serum IgE level $>100 \mathrm{kU} / \mathrm{l}$.

\section{Questionnaires}

Participants completed a detailed respiratory questionnaire incorporating validated questions from the Compendium of Respiratory Standard Questionnaires (CORSQ). ${ }^{16}$ Questions were asked to determine smoking history, passive smoking exposure, respiratory symptoms, family history, occupation and known respiratory illnesses. Wheeze was defined as a whistling sound in the chest, either high or low pitched, at any time. Cough was considered significant if it occurred more than six times a day. Phlegm production referred to mucus production from the chest and excluded mucoid discharge from the nose. To meet the criteria for chronic bronchitis, phlegm production had to occur on most days for at least 3 months of the year for two consecutive years. Chest tightness was defined as a tight or heavy feeling in the chest. Passive smoking exposure was calculated using a modified version of the system used in the Po River Delta epidemiological study.${ }^{17}$ Exposure was calculated for home, work and social places by multiplying hours per day $\times$ days per week $\times$ intensity. The three values were summed and multiplied by years of exposure to give a total exposure. Family history was a dichotomous variable defined as the presence or absence of a first degree relative with a family history of COPD, asthma, emphysema or chronic bronchitis. The occupational histories were coded using the New Zealand Standard Classification of Occupations 1999. Occupations associated with a higher risk of COPD were identified from the literature and subjects were assigned a "duration at risk" value in years. Socioeconomic status was derived from the New Zealand deprivation score, a composite of nine variables including income, employment and home ownership. Ethnicity was derived by priority coding of the responses into three groups; Maori, European and "other". The questionnaire was administered in a standardised manner by trained interviewers.

Subjects also completed a detailed questionnaire regarding their lifetime use of cannabis, which was a modified version of that used in previous studies. ${ }^{6}$ Information was obtained regarding amount, frequency, type and method of cannabis use and inhalation characteristics. The most common method of using cannabis in New Zealand is smoking a joint, in which cannabis is rolled in the form of a cigarette without the addition of tobacco. ${ }^{9}$ If subjects smoked cannabis in a form other than a joint (eg, pipes or bongs), they were asked to estimate the number of cannabis joints to which that would equate. This conversion allowed cannabis use for all participants to be quantified in terms of the total number of joints smoked. If subjects shared joints they were asked to estimate the proportion of the joint they actually smoked themselves. The total number of joint-years of cannabis smoked was calculated from the questionnaire. Subjects were additionally asked to calculate how many joints they would obtain per gram of cannabis. Both questionnaires were piloted before use.

\section{Statistical analysis}

For categorical variables, respiratory symptoms and the presence of macroscopic emphysema on CT scans, the association between cannabis and tobacco smoking, each treated as categorical predictor variables, and the presence or absence of the respiratory symptom and macroscopic emphysema was examined by logistic regression. As well as testing whether each of cannabis or tobacco smoking was associated with the symptom or CT scan result, adjusted each for the other, an interaction term was assessed to 
determine if the presence of cannabis smoking altered the association with tobacco smoking (ie, if cannabis smoking was an effect modifier as well as a confounding variable). With the relatively small number of subjects we were unable to adjust these associations for the other variables describing characteristics of the subjects. Odds ratios (ORs) for an association are reported together with $95 \%$ confidence intervals. Where an interaction term was significant at $p=0.05$, the effect of smoking cannabis on smokers of tobacco is also given.

For continuous variables, CT scan findings and pulmonary function tests, the association between cannabis and tobacco smoking was examined by analysis of covariance (ANCOVA), again treated as categorical predictor variables, together with testing for an interaction term between cannabis and tobacco smoking. These analyses were adjusted for age, sex, height, family history, passive smoking, ethnicity, atopy and years of working in an at-risk occupation. Type III sums of squares were used to check for the importance of cannabis and tobacco smoking each adjusted for the other. The adjusted difference between smokers of cannabis or tobacco smokers and nonsmokers of each substance is reported, together with how this difference was modified for tobacco smokers who also smoked cannabis where an interaction term between cannabis and tobacco smoking was significant at $p=0.05$. Normality assumptions were reasonably well met for the analyses.

As we found that smokers of cannabis and tobacco smoked less tobacco than tobacco only smokers, we also carried out ANCOVA treating cannabis and tobacco smoking as joint-years and pack-years, respectively, as detailed in the Methods section. For these analyses we adjusted for age, sex and height. Type III sums of squares were again used to evaluate the effect of each of cannabis and tobacco smoking adjusted for the other. The coefficients describing these associations show the number of units change in the particular pulmonary function variable for the amount smoked per extra joint-year for cannabis and packyear for tobacco.

\section{RESULTS}

\section{Subject characteristics}

Four hundred and forty-two volunteers presented to the clinic for screening, 103 of whom did not meet the inclusion criteria, leaving 339 for recruitment into the four smoking groups: cannabis only $(\mathrm{n}=75)$; combined cannabis and tobacco $(\mathrm{n}=91)$; tobacco only $(\mathrm{n}=92)$; non-smokers of either substance $(\mathrm{n}=81)$ (Participant flow diagram for inclusion of subjects can be found online at http://thorax.bmj.com/supplemental, figure E2). Urine testing confirmed a history of the absence of cannabis or tobacco smoking in the respective control groups. The characteristics of the participants are shown in table 1. The mean age of the four groups was similar and most of the participants were men. The distribution of ethnic groups was broadly representative of the distribution in the general population of New Zealand. Socioeconomic status was higher in the non-smoking group and the tobacco smoking group than in both cannabis smoking groups.

In the cannabis only group $(n=75)$, all subjects reported smoking joints as the predominant form of cannabis consumption. Nine of these subjects (12\%) reported having previously added tobacco to cannabis in the preparation of the joint, but in none of these subjects was this routine practice. In addition to smoking joints, 54 (72\%) reported that they had also smoked cannabis by another method such as bongs or pipes.

In the combined cannabis and tobacco group $(n=91)$, all subjects reported smoking joints as the predominant form of cannabis consumption. Twenty of these subjects $(22 \%)$ reported adding tobacco to cannabis in the preparation of the joint. In addition to smoking joints, $72(79 \%)$ reported that they had also smoked cannabis by another method such as bongs or pipes.

Cannabis smokers used similar amounts of cannabis whether or not they were also tobacco smokers. However, tobacco smokers who smoked cannabis smoked less tobacco than those who smoked tobacco alone, with a difference of 7.4 pack-years (95\% CI 3.4 to 11.4 ).

As cannabis is purchased by weight and supplies are monitored with care, subjects were able to calculate the number of joints they obtained per gram of cannabis. They reported that the most common amount of cannabis purchased was a NZ\$20 foil of median weight $1.1 \mathrm{~g}$ (range 1-5) from which the median number of joints obtained was 3 (range 17.5). From these figures it was possible to calculate that the median amount of cannabis contained in one joint was $0.37 \mathrm{~g}$, with considerable variability between subjects. As a reference, the standard weight of a tobacco cigarette is $1 \mathrm{~g}$.

\section{Associations between cannabis and tobacco use and measures of pulmonary structure, function and symptoms}

Descriptive statistics for cannabis and tobacco use and measures of pulmonary structure, function and symptoms are shown in table 2. The statistical analysis of the effects of cannabis and tobacco use on these respiratory measures are summarised in table 3. The main effects represent the differences between smokers of cannabis and non-smokers of cannabis, and smokers of tobacco and non-smokers of tobacco, respectively.

\section{Respiratory symptoms}

Wheeze was associated with cannabis smoking, OR 1.3 (1.0 to 1.6), and tobacco smoking, OR 1.4 ( 1.1 to 1.9) with no evidence of an interaction. Chest tightness was associated with cannabis smoking, OR 1.4 (1.1 to 1.7), but not with tobacco smoking, OR 1.1 (0.9 to 1.3). Cough was associated with cannabis smoking, OR 1.5 ( 1.1 to 2.0 ), and tobacco smoking, OR 1.9 (1.4 to 2.6), however there was evidence of an interaction. The apparent effect of being a combined cannabis and tobacco smoker was to attenuate this association. For example, in tobacco smokers

Table 1 Characteristics of study participants

\begin{tabular}{lllll}
\hline & $\begin{array}{l}\text { Cannabis only } \\
(\mathbf{N}=75)\end{array}$ & $\begin{array}{l}\text { Cannabis + tobacco } \\
(\mathbf{N}=91)\end{array}$ & $\begin{array}{l}\text { Tobacco only } \\
(\mathbf{N}=92)\end{array}$ & $\begin{array}{l}\text { Non-smoker } \\
(\mathbf{N = 8 1 )}\end{array}$ \\
\hline Mean (SD) age (years) & $42.5(9.7)$ & $41.3(9.2)$ & $46.0(10.0)$ & $43.7(10.3)$ \\
Men, N (\%) & $67(89.3)$ & $62(68.1)$ & $77(83.7)$ & $65(80.3)$ \\
Mean (SD) height (m) & $1.75(0.07)$ & $1.73(0.08)$ & $1.74(0.09)$ & $1.75(0.09)$ \\
Caucasian, N (\%) & $68(90.7)$ & $74(82.2)$ & $88(95.7)$ & $75(92.6)$ \\
Mean (SD) joint-years & $54.2(75.3)$ & $46.0(44.0)$ & - & - \\
Mean (SD) pack-years & - & $16.1(11.5)$ & $23.5(15.8)$ & - \\
Median (interquartile range) deprivation score & $5(2-8)$ & $4(3-7)$ & $3(1-5)$ & $2(1-5)$ \\
(10=most deprived) & & & & \\
\hline
\end{tabular}


Table 2 High-resolution $\mathrm{CT}(\mathrm{HRCT})$, lung function and respiratory symptom findings for the four groups, classified according to smoking status

\begin{tabular}{|c|c|c|c|c|}
\hline & $\begin{array}{l}\text { Cannabis only } \\
(\mathrm{N}=75)\end{array}$ & $\begin{array}{l}\text { Cannabis + tobacco } \\
(\mathrm{N}=91)\end{array}$ & $\begin{array}{l}\text { Tobacco only } \\
(\mathrm{N}=92)\end{array}$ & $\begin{array}{l}\text { Non-smoker } \\
(\mathrm{N}=81)\end{array}$ \\
\hline \multicolumn{5}{|l|}{ HRCT } \\
\hline $\begin{array}{l}\text { Mean (SD) RA950* apical } \\
\text { slice (\%) }\end{array}$ & $10.8(7.3)$ & $10.6(7.8)$ & $8.3(7.3)$ & $8.6(6.1)$ \\
\hline $\begin{array}{l}\text { Mean (SD) RA950 mean of } \\
3 \text { slices (\%) }\end{array}$ & $12.3(6.7)$ & $10.8(6.3)$ & $9.6(6.9)$ & $10.5(6.3)$ \\
\hline $\begin{array}{l}\text { Macroscopic emphysema, } \\
\mathrm{N}(\%)\end{array}$ & $1(1.3)$ & $15(16.5)$ & $17(18.5)$ & $0(0)$ \\
\hline \multicolumn{5}{|l|}{ Lung function } \\
\hline Mean (SD) FEV $1 / F V C(\%)$ & $76.2(6.6)$ & $76.6(7.4)$ & 74.7 (7.5) & $79.7(5.4)$ \\
\hline Mean (SD) FEV (I) & $4.17(0.7)$ & $3.90(0.9)$ & $3.73(0.8)$ & $4.22(0.9)$ \\
\hline Mean (SD) sGaw (/s.kPa) & $1.2(0.4)$ & $1.2(0.4)$ & $1.3(0.4)$ & $1.5(0.5)$ \\
\hline Mean (SD) TLC (I) & $7.6(1.1)$ & $7.2(1.3)$ & $7.2(1.2)$ & $7.4(1.3)$ \\
\hline Mean (SD) RV (I) & $2.0(0.5)$ & $1.9(0.5)$ & $2.1(0.6)$ & $2.0(0.4)$ \\
\hline Mean (SD) FRC (I) & $3.8(0.8)$ & $3.8(0.9)$ & $3.7(0.8)$ & $3.7(0.8)$ \\
\hline $\begin{array}{l}\text { Mean (SD) TLCO/VA } \\
(\mathrm{mmol} / \mathrm{min} / \mathrm{kPa} / \mathrm{l})\end{array}$ & $1.56(0.2)$ & $1.45(0.2)$ & $1.43(0.2)$ & $1.57(0.2)$ \\
\hline $\begin{array}{l}\text { Mean (SD) MMEF (I/min) } \\
\text { Respiratory symptoms }\end{array}$ & $213.2(62)$ & $202.8(77)$ & $181.2(67)$ & $238.0(73)$ \\
\hline Wheeze, $\mathrm{N}(\%)$ & $20(26.7)$ & $31(34.1)$ & $28(30.4)$ & $9(11.1)$ \\
\hline Cough, N (\%) & $22(29.3)$ & $26(28.6)$ & $37(40.2)$ & $4(4.9)$ \\
\hline Chest tightness, $N(\%)$ & $37(49.3)$ & $49(53.9)$ & $34(40.0)$ & $28(34.6)$ \\
\hline $\begin{array}{l}\text { Symptoms of chronic } \\
\text { bronchitis, N (\%) }\end{array}$ & 14 (18.7) & $28(30.8)$ & $12(13.0)$ & $2(2.5)$ \\
\hline \multicolumn{5}{|c|}{$\begin{array}{l}\mathrm{FEV}{ }_{1} \text {, forced expiratory volume in } 1 \mathrm{~s} ; \mathrm{FRC} \text {, functional residual capacity; FVC, forced vital capacity; MMEF, maximum } \\
\text { mid-expiratory flow; RV, residual volume; } \mathrm{sGaw} \text {, specific airways conductance; } \mathrm{TLC} \text {, total lung capacity; } \mathrm{TLCO} / \mathrm{V}_{\mathrm{A}} \text {, } \\
\text { carbon monoxide transfer coefficient. } \\
\text { *RA950, relative area of lung occupied by attenuation values lower than }-950 \text { Hounsfield units as a percentage of the } \\
\text { total lung area. }\end{array}$} \\
\hline
\end{tabular}

who also smoked cannabis the association with cough had an OR of 1.0 (0.7 to 1.4), indicating that for combined smokers of tobacco and marijuana there was no association with cough. Chronic bronchitis, defined as daily sputum production for at least 3 months of the year for greater than 2 years duration, was associated with cannabis use, OR 2.0 (1.4 to 2.7), and tobacco use, OR 1.6 ( 1.2 to 2.2 ). The presence of asthma diagnosed after the age of 16 years was associated with cannabis use, OR 1.7 ( 1.0 to 2.9), but not tobacco, OR 1.2 (0.7 to 1.9 ).

\section{Lung function tests}

Table 3 shows the main effects of cannabis and tobacco on the lung function tests. There was no statistically significant interaction between cannabis and tobacco smoking on TLC and TLCo/VA but, for $\mathrm{FEV}_{1} / \mathrm{FVC}, \mathrm{FEV}_{1}, \mathrm{MMEF}$ and sGaw, there was a statistically significant interaction. Both cannabis and tobacco smoking were associated with a reduction in the $\mathrm{FEV}_{1} / \mathrm{FVC}$ ratio, but the effect of cannabis was only of marginal statistical

Table 3 Continuous variables: main effects of cannabis and tobacco smoking

\begin{tabular}{lcc}
\hline Variable & $\begin{array}{l}\text { Cannabis smoking } \\
\text { OR (95\% Cl) }\end{array}$ & $\begin{array}{l}\text { Tobacco smoking } \\
\text { OR (95\% Cl) }\end{array}$ \\
\hline RA950 apical slice (\%) & $3.3(1.8$ to 4.8$)$ & $0.1(-1.4$ to 1.6$)$ \\
RA950 mean of 3 slices (\%) & $2.4(1.0$ to 3.8$)$ & $-0.6(-2.0$ to 0.8$)$ \\
FEV $/$ FVC (\%) & $-1.1(-2.6$ to 0.1$)$ & $-2.5(-4.0$ to -1.1$)$ \\
FEV (I) & $-0.01(-0.13$ to 0.11$)$ & $-0.2(-0.33$ to -0.09$)$ \\
sGaw (/s.kPa) & $-0.12(-0.21$ to -0.03$)$ & $-0.08(-0.17$ to 0.01$)$ \\
TLC (I) & $0.14(-0.02$ to 0.31$)$ & $-0.08(-0.24$ to 0.09$)$ \\
RV (I) & $0.02(-0.07$ to 0.10$)$ & $0.04(-0.05$ to 0.12$)$ \\
FRC (I) & $0.11(-0.04$ to 0.26$)$ & $0.04(-0.11$ to 0.19$)$ \\
TLCO/VA (mmol/min/kPa/l) & $-0.01(-0.05$ to 0.03$)$ & $-0.11(-0.16$ to -0.07$)$ \\
MMEF (I/min) & $-4.94(-19.3$ to 9.4$)$ & $-25.2(-39.5$ to -11.0$)$ \\
\hline
\end{tabular}

$\mathrm{FEV}_{1}$, forced expiratory volume in $1 \mathrm{~s} ; \mathrm{FRC}$, functional residual capacity; FVC, forced vital capacity; MMEF, maximum mid-expiratory flow; RV, residual volume; sGaw, specific airways conductance; SVC, slow vital capacity; TLC, total lung capacity; TLCO/VA, carbon monoxide transfer coefficient. significance. The effect of cannabis smoking in those who smoke tobacco was to attenuate this effect by $0.8 \%$ (95\% CI $-1.8 \%$ to $3.4 \%)$. Cannabis smoking had no effect on $\mathrm{FEV}_{1}$ but tobacco smoking reduced it. The effect of cannabis smoking on those who smoke tobacco was to attenuate this effect by 0.13 litres (95\% CI 0.08 to 0.36 ). Cannabis had no statistically significant effect on MMEF and tobacco smoking reduced it. The effect of cannabis on smokers was to attenuate this effect by $14.9 \mathrm{l} / \mathrm{s}$ (95\% CI -10.5 to 40.2). Cannabis increased TLC with marginal statistical significance but tobacco had no effect on TLC. Neither cannabis nor tobacco had a statistically significant effect on RV or FRC. Cannabis and tobacco use reduced sGaw, although the effect was of marginal statistical significance for tobacco. Although the interaction term was statistically significant, cannabis smoking did not further reduce sGaw in those who smoked tobacco $(-0.02$ (95\% CI -0.18 to 0.14$)$ ). For TLCo/VA (adjusted), cannabis had no effect while tobacco smoking reduced this measurement.

\section{High-resolution CT scanning}

Cannabis smoking was associated with an increased percentage of low density lung tissue both on the apical slice and the mean of the three slices but tobacco smoking showed no such association and there was no evidence of an interaction (table 3). Tobacco smoking was associated with the presence of macroscopic emphysema (OR 5.7 (95\% CI 2.1 to 15.6)) while cannabis smoking was not (OR 1.0 (95\% CI 0.7 to 1.4)). An interaction term could not be calculated for macroscopic emphysema. In the two tobacco smoking groups (with and without cannabis) there was no difference in the distribution of emphysema (centrilobular versus paraseptal). The one cannabis only subject with macroscopic emphysema had a 437 joint-year history.

\section{Cannabis and tobacco use as continuous variables}

Cannabis use, analysed as joint-years, predicted $\mathrm{FEV}_{1} / \mathrm{FVC}$ ratio, sGaw, FRC and TLC, but was not associated with $\mathrm{FEV}_{1}$, TLCO/VA or MMEF. Tobacco use was also associated with $\mathrm{FEV}_{1} /$ FVC ratio, FRC and sGaw but not with TLC. The regression 
coefficients describing some of the associations are shown in table 4. The interpretation of these coefficients is the number of units change for the respiratory response variable per unit change in joint-years of cannabis or pack-years of tobacco smoked. For example, the $\mathrm{FEV}_{1} / \mathrm{FVC}$ ratio, expressed as a percentage, decreased by $1.5 \%$ for each 10 pack-years of tobacco smoking. One pack-year of tobacco was equivalent to 7.9, 4.4 and 4.1 joint-years for the effect on $\mathrm{FEV}_{1} / \mathrm{FVC}, \mathrm{FRC}$ and sGaw, respectively. As 1 pack-year represents 20 cigarettes per day for 1 year, it could be calculated that one joint was equivalent to $2.5-5$ tobacco cigarettes for the effect on $\mathrm{FEV}_{1} / \mathrm{FVC}, \mathrm{FRC}$ and sGaw.

\section{DISCUSSION}

This study has identified the nature and magnitude of the effects of cannabis smoking on respiratory structure, function and symptoms. There was a dose-response relationship of cannabis smoking with airflow obstruction, impaired large airways function and hyperinflation. For measures of airflow obstruction, one joint of cannabis had a similar effect to that of 2.5-5 tobacco cigarettes. In contrast, cannabis smoking was uncommonly associated with macroscopic emphysema, which was present almost entirely in the tobacco smoking groups.

There are several methodological issues relevant to the interpretation of the results. The first was the inability to identify a sufficient number of cannabis smokers from the random population sample. Despite starting with an initial postal questionnaire of 3500 adults, only 19 met the criteria for smoking at least 5 joint-years with no other illegal drug use and no chronic respiratory disorder such as asthma in childhood. It was apparent that it was not possible to use a random population sample for a study of this nature and, as previously, ${ }^{6}$ a convenience sample was used. While this approach incurred the risk of selection bias by preferentially attracting people concerned about their respiratory health, this applies equally to all subject groups. We applied strict exclusion criteria for other illegal drug use due to their potential respiratory effects. ${ }^{18}$ This meant that many potential participants were ineligible, particularly the heaviest cannabis users who were more likely to have used other drugs. As a result, these criteria preferentially excluded such heavy users, suggesting that the effects observed may represent a conservative estimate.

The requirement for tobacco smokers to have a history of at least 1 pack-year was based on the data that tobacco smokers need to smoke in excess of this amount to develop abnormal lung function. ${ }^{19}$ The requirement for cannabis smokers to have a history of at least 5 joint-years was based on the data that one cannabis joint results in three to five times higher levels of carbon monoxide and tar deposition, respectively, ${ }^{20}$ thereby achieving an a priori equivalence between the lower limit of cannabis and tobacco smoking levels. It also ensured that experimental users who did not smoke cannabis habitually were excluded.

Cannabis remains illegal in New Zealand although participants were willing to volunteer under the assurance of strict confidentiality. All subjects in the groups with no cannabis or

Table 4 Regression coefficients for association between selected lung function variables and cannabis and tobacco use

\begin{tabular}{lll}
\hline $\begin{array}{l}\text { Lung function } \\
\text { variable }\end{array}$ & $\begin{array}{l}\text { Cannabis association } \\
\text { per joint-year } \\
\text { OR }(95 \% \mathrm{Cl})\end{array}$ & $\begin{array}{l}\text { Tobacco association } \\
\text { per pack-year } \\
\text { OR }(95 \% \mathrm{Cl})\end{array}$ \\
\hline FEV $/$ FVC ratio & $-0.019(-0.033$ to -0.0048$)$ & $-0.15(-0.20$ to -0.096$)$ \\
sGaw (/s.kPa) & $-0.0017(-0.0026$ to -0.0009$)$ & $-0.007(-0.01$ to -0.004$)$ \\
FRC (I) & $0.0013(-0.00013$ to 0.0027$)$ & $0.0057(0.0005$ to 0.0109$)$ \\
TLC (I) & $0.002(0.0004$ to 0.004$)$ & $-0.0006(-0.006$ to 0.005$)$ \\
\hline
\end{tabular}

$\mathrm{FEV}_{1}$, forced expiratory volume in $1 \mathrm{~s}$; FRC, functional residual capacity; FVC, forced vital capacity; sGaw, specific airways conductance; TLC, total lung capacity. no tobacco use had negative samples for THC or cotinine, demonstrating the honest reporting of the subjects in this regard. A further problem is that cannabis use is often difficult to quantify precisely due to smokers sharing joints, different inhalation techniques and different ways of smoking cannabis including joints, pipes and bongs. In order to standardise use, subjects were asked to estimate the "joint equivalent" used by these methods to enable cannabis use to be expressed as jointyears of use. In our community the median amount of cannabis in a joint was $0.37 \mathrm{~g}$, although there was considerable variability in the amount of cannabis in joints prepared by different subjects. By comparison, the average amount of tobacco in a commercial cigarette of standard length is $1 \mathrm{~g}$.

Although the calculation of joint-years was based on subjects' self-reports, there is evidence that cannabis use is more accurately reported than other drugs ${ }^{21}$ and self-reports have been shown to correlate well with urinary THC levels. ${ }^{22}$ Influential factors in increasing the validity of self-reported drug use include privacy, anonymity and credibility of the study. Every effort was made to create a relaxed and confidential environment to increase the accuracy of reporting, and all subjects gave informed consent.

The practice of combining cannabis and tobacco within a joint is relatively uncommon in New Zealand. ${ }^{9}$ In our sample of cannabis only smokers, $12 \%$ had combined their cannabis with tobacco on some occasions although it was not routine practice in any of these subjects. As a result, the small quantities of tobacco used by cannabis only smokers were unlikely to significantly affect the results.

As this study was exploratory, caution must be used in interpreting the presence or absence of associations. In particular, we analysed a number of measures of pulmonary structure, function and symptoms without any adjustment for the inflation of type I error that may ensue. For some variables where we failed to find associations, this may reflect a relative lack of statistical power for any individual analysis.

The most important finding was that one joint of cannabis was similar to $2.5-5$ tobacco cigarettes in terms of causing airflow obstruction. This dose equivalence is consistent with the reported 3-5-fold greater levels of carboxyhaemoglobin and tar inhaled when smoking a cannabis joint compared with a tobacco cigarette of the same size. ${ }^{20}$ This pattern is likely to relate to the different characteristics of the cannabis joint and the way in which it is smoked. Cannabis is usually smoked without a filter ${ }^{23}$ and to a shorter butt length, ${ }^{24}$ and the smoke is a higher temperature. Furthermore, cannabis smokers inhale more deeply, ${ }^{20}$ hold their breath for longer ${ }^{20}$ and perform the Valsalva manoeuvre at maximal breath hold..$^{25}$

Our findings have extended previous observations that the principal physiological impairment with long-term cannabis smoking is on large airway function ${ }^{6}$ by demonstrating a doseresponse relationship for sGaw. Similarly, a dose-response relationship was observed with measures of airflow obstruction and hyperinflation which are a consequence of the large airways impairment. Previous research has shown that this large airways impairment is probably due to the inflammation and oedema that occurs in the tracheobronchial mucosa of cannabis smokers, ${ }^{26}$ as well as mucus hypersecretion. ${ }^{27}$ It is well recognised that an increase in airway resistance leads to hyperinflation. ${ }^{28}$ These effects are also likely to contribute to the increased prevalence of symptoms of wheezing, cough and sputum production associated with cannabis smoking, resulting in the twofold increased prevalence of chronic bronchitis. These findings are unlikely to be due to pre-existing disease as subjects were excluded if they had chronic lung disease diagnosed by a doctor before the age of 16 years.

Another novel finding was the effect of cannabis smokingbut not tobacco smoking-on lung density, which has been 
proposed as a marker of emphysema. ${ }^{29}{ }^{30}$ However, we and others have observed that decreased lung density may not be specific to emphysema ${ }^{10}{ }^{31-34}$ and correlates more closely with markers of airflow obstruction and hyperinflation. ${ }^{11}$ As a result, we have interpreted our lung density findings as being predominantly due to the effect of cannabis smoking on airflow obstruction and hyperinflation rather than causing emphysema. This interpretation is consistent with our finding that macroscopic emphysema was present almost entirely in the tobacco smoking groups. Furthermore, tobacco-but not cannabis use-was associated with a significant reduction in TLCO, the most specific lung function measure of emphysema in subjects with airflow obstruction. ${ }^{35}$ Thus, while a case series has shown that heavy cannabis smoking may cause macroscopic emphysema at a young age with a characteristic apical paraseptal pattern, ${ }^{8}$ our findings would suggest that this is not a common complication with the amount of cannabis smoked in New Zealand. Importantly, it suggests that cannabis does not cause emphysema when smoked in sufficient quantities to cause airflow obstruction, hyperinflation and chronic bronchitis.

Finally, we observed that, whereas cannabis smokers used similar amounts of cannabis whether or not they were tobacco smokers as well, tobacco smokers who used cannabis smoked less tobacco than those who smoked tobacco alone. Similarly, a study from the USA reported that, whereas cannabis users more often smoked tobacco, they were less likely than never cannabis users to be heavy long-term users of tobacco, as defined by a level of $>30$ pack-years. ${ }^{36}$ However, this lesser amount of tobacco in combined users did not result in reduced adverse respiratory effects compared with tobacco only smokers because of the additional effects of the cannabis use.

In conclusion, these findings suggest that the predominant effects of cannabis on pulmonary structure, function and symptoms are in causing the symptoms of wheezing, cough, chest tightness and sputum production, large airways obstruction and hyperinflation, but not emphysema. The dose equivalence of 1:2.5-5 between cannabis joints and tobacco cigarettes in causing airflow obstruction is of major public health significance.

\section{ACKNOWLEDGEMENTS}

The authors thank the subjects who participated in the study and Denise Fabian, Avrille Holt, Patricia Heuser, Eleanor Chambers, Andrew Kingzett-Taylor and the radiology and administrative staff of Pacific Radiology Ltd for their contribution to this study.

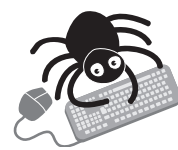

Further data are given in figs E1 and E2 in the online supplement available at http://thorax.bmi.com/ supplemental.

\section{Authors' affiliations \\ Sarah Aldington, Mathew Williams, Alison Pritchard, Amanda McNaughton, Geoffrey Robinson, Richard Beasley, Medical Research Institute of New Zealand, Wellington, New Zealand \\ Mike Nowitz, Pacific Radiology, Wakefield Hospital, Wellington, and Wellington School of Medicine and Health Sciences, Wellington, New Zealand \\ Mark Weatherall, Wellington School of Medicine and Health Sciences, Wellington, New Zealand}

Funding was provided by the New Zealand Ministry of Health, the Hawke's Bay Medical Research Foundation and GlaxoSmithKline (UK).

Competing interests: None.

\section{REFERENCES}

1 United Nations Office on Drugs and Crime. World Drug Report 2006;1.

2 Hoffmann D, Brunnerman D, Gori G, et al. On the carcinogenicity of marijuana smoke. Recent Advances Phytochem 1975;9:63-81.
3 Bloom J, Kaltenborn W, Paoletti P, et al. Respiratory effects of non-tobacco cigarettes. BMJ 1987;295:1516-8.

4 Taylor R, Fergusson D, Milne B, et al. A longitudinal study of the effects of tobacco and cannabis exposure on lung function in young adults. Addiction 2002;97:1055-61.

5 Sherrill D, Krzyzanowski M, Bloom J, et al. Respiratory effects of non-tobacco cigarettes: a longitudinal study in general population. Int J Epidemiol $1991 ; 20: 132-7$

6 Tashkin D, Coulson A, Clark V, et al. Respiratory symptoms and lung function in habitual heavy smokers of marijuana alone, smokers of marijuana and tobacco, smokers of tobacco alone and non smokers. Am Rev Respir Dis 1987; 135:209-16.

7 Tashkin D, Simmons M, Sherrill D, et al. Heavy habitual marijuana smoking does not cause an accelerated decline in $\mathrm{FEV}_{1}$ with age. Am J Respir Crit Care Med 1997; 155:141-8

8 Johnson M, Smith R, Morrison D, et al. Large lung bullae in marijuana smokers. Thorax 2000:55:340-2.

9 Wilkins C, Girling M, Sweetsur P, et al. Cannabis and other illicit drug trends in New Zealand, 2005. Auckland: Massey University, 2005.

10 Marsh S, Aldington S, Williams $M$, et al. Utility of lung density measurements in the diagnosis of emphysema. Respir Med 2007;101:1512-20.

11 Marsh S, Aldington S, Williams M, et al. Physiological associations of computerized tomography lung density: a factor analysis. Int J COPD 2006;1:181-7.

12 Quanjer P, Dalhuijsen A, van Zomeren B. Standardization of lung function tests. Report of the Working Party for Standardization of Lung Function Tests. European Community for Coal and Steel. Bull Eur Physiopathol Respir 1983;19:45-51

13 American Thoracic Society. Standardization of spirometry: 1994 update. Am J Respir Crit Care Med 1994;152:1107-36.

14 American Thoracic Society. Single-breath carbon monoxide diffusing capacity (transfer factor): recommendations for a standard technique. Am J Respir Crit Care Med 1995; 152:2185-98.

15 Coates A, Peslin R, Rodenstein D, et al. ERS/ATS workshop report series: Measurement of lung volumes by plethysmography. Eur Respir J 1997; 10:1415-27.

16 Pistelli F, Viegi G, Carrozzi L, et al. Appendix 3: Compendium of respiratory standard questionnaires for adults (CORSQ). Eur Respir Rev 2001;11:118-43.

17 Simoni M, Carrozzi L, Baldacci S, et al. Characteristics of women exposed and unexposed to environmental tobacco smoke (ETS) in a general population sample of North Italy (Po River Delta epidemiological study). Eur J Epidemiol 2001;17:363-8.

18 Tashkin D. Airway effects of marijuana, cocaine, and other inhaled illicit agents Curr Opin Pulm Med 2001;7:43-61.

19 Lange P, Parner J, Vestbo J, et al. A 15-year follow-up study of ventilatory function in adults with asthma. N Engl J Med 1998;339:1194-2000.

20 Wu T, Tashkin D, Diahed B, et al. Pulmonary hazards of smoking marijuana as compared with tobacco. N Engl J Med 1988;318:347-51.

21 Hser Y-I, Maglione M, Boyle K. Validity of self-report of drug use among STD patients, ER patients, and arrestees. Am J Drug Alcohol Abuse 1999;25:81-91.

22 Martin G, Wilkinson D, Kapur B. Validation of self-reported cannabis use by urine analysis. Addict Behav 1988;13:147-50.

23 Rickert W, Robinson J, Rogers B. A comparison of tar, carbon monoxide and PH levels in smoke from marijuana and tobacco cigarettes. Can J Public Health 1982;73:386-91.

24 Tashkin D, Gliederer F, Rose J, et al. Tar, CO and THC delivery from the 1st and 2nd halves of a marijuana cigarette. Pharmacol, Biochem Behavior 1991;40:657-61.

25 Birrer R, Calderon J. Pneumothorax, pneumomediastinum and pneumopericardium following Valsalva's maneuver during marijuana smoking NY State J Med 1984;84:619-20.

26 Sarafian TA, Magallanes JA, Shau $\mathrm{H}$, et al. Oxidative stress produced by marijuana smoke. Am J Respir Cell Mol Biol 1999;20:1286-93.

27 Gong H, Fligiel S, Tashkin D, et al. Tracheobronchial changes in habitual, heavy smokers of marijuana with and without tobacco. Am Rev Respir Dis 1987;136:142-9.

28 Pellegrino R, Brusasco V. On the causes of lung hyperinflation during bronchoconstriction. Eur Respir J 1997;10:468-75.

29 Gevenois $\mathbf{P}$, de Maertelaer V, de Vuyst $P$, et al. Comparison of computed density and macroscopic morphometry in pulmonary emphysema. Am J Respir Crit Care Med 1995;152:653-7.

30 Gevenois $\mathbf{P}$, de Vuyst $\mathrm{P}$, de Maertelaer V, et al. Comparison of computed density and microscopic morphometry in pulmonary emphysema. Am J Respir Crit Care Med 1996; 154:187-92.

31 Mishima M, Hirai $\mathrm{T}$, Itoh $\mathrm{H}$, et al. Complexity of terminal airspace geometry assessed by lung computed tomography in normal subjects and patients with chronic obstructive airways disease. Proc Natl Acad Sci USA 1999;96:8829-34.

32 Newman K, Lynch D, Newman L, et al. Quantitative computed tomography detects air trapping due to asthma. Chest 1994;106:105-9.

33 Biernacki W, Redpath A, Best J, et al. Measurement of CT lung density in patients with chronic asthma. Eur Respir J 1997;10:2455-9

34 Mitsunobu F, Mifune T, Ashida K, et al. Influence of age and disease severity on high resolution CT lung densitometry in asthma. Thorax 2001:56:851-6.

35 Pellegrino R, Viegi G, Brusasco V, et al. ATS/ERS Task Force: Standardisation of lung function testing. Interpretative strategies for lung function tests. Eur Respir J 2005;26:948-68

36 Rosenblatt KA, Daling JR, Chen C, et al. Marijuana use and risk of oral squamous cell carcinoma. Cancer Res 2004;64:4049-54. 
Therapeutic CPAP improved glycaemic control after 3 months in our subjects with diabetes. Changes in body composition may play a role. Unfortunately, bioelectrical impedance analysis, as used in all studies, has its limitations. ${ }^{3}$

It would be very interesting to know whether there is an effect of CPAP therapy on insulin sensitivity in less obese diabetic subjects as we demonstrated a rapid improvement in insulin sensitivity in our study in the non-diabetic OSAS group in those with a BMI $<30 \mathrm{~kg} / \mathrm{m}^{2}$. That this early effect of CPAP may be related to acclimatisation to the conditions of the sleep laboratory and the clamp procedure is questionable as our studies were done under exactly the same conditions and there is no reason to postulate a higher stress sensitivity in leaner patients.

Although we could not measure plasma catecholamines, we were able to re-measure serum cortisol as another marker of sympathetic stimulation in 20 individuals in our study, ${ }^{1}$ and could not find significant differences before (mean 19.18 (SD 3.52) $\mu \mathrm{g} / \mathrm{dl}$ ) and 2 days after $(19.35(3.27) \mu \mathrm{g} / \mathrm{dl})$ onset of CPAP therapy $(p=0.59)$.

\section{A Harsch, E G Hahn, S Pour Schahin}

Medical Department 1, Friedrich-Alexander University of Erlangen-Nuremberg, Erlangen, Germany

Correspondence to: Dr I A Harsch, Department of Medicine I, Friedrich-Alexander University ErlangenNuremberg, Ulmenweg 18, 91054 Erlangen, Germany; igor.harsch@uk-erlangen.de

Competing interests: None.

Thorax 2008;63:384-385. doi:10.1136/thx.2007.090415

\section{REFERENCES}

1. Harsch IA, Pour Schahin S, Radespiel-Tröger M, et al. Continuous positive airway pressure treatment rapidly improves insulin sensitivity in patients with obstructive sleep apnea syndrome. Am J Respir Crit Care Med 2004;169:156-62.

2. Harsch IA, Schahin SP, Brückner K, et al. The effect of continuous positive airway pressure treatment on insulin sensitivity in patients with obstructive sleep apnoea syndrome and type 2 diabetes. Respiration 2004;71:252-9.

3. Bioelectrical impedance analysis in body composition measurement. NIH Technol Assess Statement Online 1994 December 12-14. http://www.ncbi.nlm.nih.gov/ books/bv.fcgi?rid = hstat4. section.26000 (accessed 15 January 2008).

\section{Authors' reply}

We thank Harsch et al for their comments. Their letter highlights the important contribution of obesity in studies of both insulin resistance and obstructive sleep apnoea (OSA). Although obesity underlies both pathologies, it also confounds studies investigating these conditions. The only studies therefore that can determine conclusively the effect of continuous positive airway pressure (CPAP) on improvements in insulin resistance and glycaemia in patients with OSA are double blind randomised controlled trials. We agree that a randomised controlled trial of CPAP in less obese subjects with type 2 diabetes would clarify this area further, but a study of pre-diabetic subjects with insulin resistance would be even more enlightening.

\section{S West, J Stradling}

Oxford Centre for Respiratory Medicine, Churchill Hospital, Oxford, UK

Correspondence to: Professor J Stradling, Oxford Centre for Respiratory Medicine, Churchill Hospital, Oxford OX3 7LJ, UK; john.stradling@orh.nhs.uk

Competing interests: None.

\section{Mould eradication and asthma}

The paper by Burr et $a l^{1}$ on the efficacy of eradicating visible indoor mould on respiratory health in patients with asthma is of great interest, but I think the authors underestimate the clinical relevance of their findings because they overestimate the lack of effect on peak expiratory flow (PEF) variability as an objective assessment of their intervention. The lack of effect on this primary end point in the presence of highly significant effects on medication use and symptoms - even after 12 months-simply illustrates once again that PEF is too insensitive to contribute meaningfully to the interpretation of our therapeutic interventions. The study by Burr et $a l^{1}$ and those of others ${ }^{23}$ are examples of investigations that demonstrate a lack of efficacy using PEF parameters as primary end points whereas the secondary end points-such as respiratory symptoms-demonstrate efficacy of the interventions. Increased PEF variability is a specific feature of unstable asthma but it is not necessarily a sensitive one. PEF mainly reflects central airway mechanics ${ }^{4}$ and is therefore not the optimal monitoring tool because asthma predominantly affects the smaller airways. Hence, PEF may severely underestimate peripheral airway patency. Clinical studies are much more convincing and powerful if sensitive and relevant end points are chosen, and I would strongly advocate using end points that are both relevant and sensitive. This will teach us more and provide more credit for all involved-doctors as well as patients.

\section{P J F M Merkus}

Correspondence to: Dr P J F M Merkus, Radboud University Children's Hospital, P 0 Box 9101, Nijmegen 6500 HB, The Netherlands; p.merkus@cukz.umcn.nl

Competing interests: None.

\section{REFERENCES}

1. Burr ML, Matthews IP, Arthur RA, et al. Effects on patients with asthma of eradicating visible indoor mould: a randomised controlled trial. Thorax 2007;62:767-72.

2. Papi A, Canonica GW, Maestrelli P, et al. Rescue use of beclomethasone and albuterol in a single inhaler for mild asthma. N Engl J Med 2007;356:2040-52.

3. Boushey HA, Sorkness CA, King TS, et al. Daily versus as-needed corticosteroids for mild persistent asthma. N Engl J Med 2005;352:1519-28.

4. Pedersen OF, Brackel HJ, Bogaard JM, Kerrebijn KF. Wave-speed-determined flow limitation at peak flow in normal and asthmatic subjects. J App/ Physiol 1997;83:1721-32.

\section{CORRECTIONS}

doi:10.1136/thx.2006.077081 corr1

The label "OR (odds ratio)" was erroneously introduced into the headings to tables 3 and 4 in the paper by Aldington et al (Thorax 2007;62:1058-63). In table 3, the numbers in the columns refer to the estimates of the difference of the particular measurement of respiratory function between those who do and those who do not smoke tobacco, and those who do and do not smoke cannabis, respectively. The heading in table 4 refers incorrectly to OR for association between tobacco pack years or cannabis joint years and the measurement of respiratory function. The numbers in the columns refer to the change in the particular measurement of respiratory function per unit change of pack years and joint years respectively. The "OR" label should be omitted from these tables.

\section{doi:10.1136/thx.2007.083592corr1}

We would like to draw readers' attention to a typographical error in the article by Chapman et al (Thorax 2008;63:228-33). In the discussion, the antigen CAGE is referred to as CAGE (DDX58) and should read CAGE (DDX48); however, the corresponding references are correct. The section is given in full below:

"The DEAD-box cancer testis antigen CAGE (DDX48) has previously been shown to be expressed in a number of cancers including gastric, cervical and lung cancer tissue and cell lines, and autoantibodies have been reported to this protein in some but not all of the cancers samples studied. ${ }^{25 "}$ 